\title{
Integrating precision medicine in the study and clinical treatment of a severely mentally ill person
}

Background: In recent years, there has been an explosion in the number of technical and medical diagnostic platforms being developed. This has greatly improved our ability to more accurately, and more comprehensively, explore and characterize human biological systems on the individual level. Large quantities of biomedical data are now being generated and archived in many separate research and clinical activities, but there exists a paucity of studies that integrate the areas of clinical neuropsychiatry, personal genomics and brainmachine interfaces. Methods: A single person with severe mental illness was implanted with the Medtronic Reclaim® Deep Brain Stimulation (DBS) Therapy device for Obsessive Compulsive Disorder (OCD), targeting his nucleus accumbens / anterior limb of the internal capsule. Programming of the device and psychiatric assessments occurred in an outpatient setting for over two years. His genome was sequenced and variants were detected in the Illumina Whole Genome Sequencing Clinical Laboratory Improvement Amendments (CLIA)certified laboratory. Results: We report here the detailed phenotypic characterization, clinicalgrade whole genome sequencing (WGS), and two-year outcome of a man with severe OCD treated with DBS. Since implantation, this man has reported steady improvement, highlighted by a steady decline in his Yale-Brown Obsessive Compulsive Scale (YBOCS) score from 38 to a score of $\sim 25$. A rechargeable Activa $\mathrm{RC}$ neurostimulator battery has been of major benefit in terms of facilitating a degree of stability and control over the stimulation. His psychiatric symptoms reliably worsen within hours of the battery becoming depleted, thus providing confirmatory evidence for the efficacy of DBS for OCD in this person. WGS revealed that he is a heterozygote for the $p$.Val66Met variant in BDNF, encoding a member of the nerve growth factor family, and which has been found to predispose carriers to various psychiatric illnesses. He carries the p.Glu429Ala allele in methylenetetrahydrofolate reductase (MTHFR) and the p.Asp7Asn allele in ChAT, encoding choline O-

acetyltransferase, with both alleles having been shown to confer an elevated susceptibility to PeerJ reviewing PDF | (v2013:06:578:2:0:NEW 14 Sep 2013) 
psychoses. We have found thousands of other variants in his genome, including

pharmacogenetic and copy number variants. This information has been archived and offered to this person alongside the clinical sequencing data, so that he and others can re-analyze his genome for years to come. Conclusions: To our knowledge, this is the first study in the clinical neurosciences that integrates detailed neuropsychiatric phenotyping, deep brain stimulation for OCD and clinical-grade WGS with management of genetic results in the medical treatment of one person with severe mental illness. We offer this as an example of precision medicine in neuropsychiatry including brain-implantable devices and genomicsguided preventive health care. 
1 Jason A. O’Rawe ${ }^{1,2}$, Han Fang ${ }^{1,2}$, Shawn Rynearson ${ }^{3}$, Reid Robison ${ }^{4}$, Edward S. Kiruluta ${ }^{5}$, Gerald

2 Higgins $^{6}$, Karen Eilbeck ${ }^{3}$, Martin G. Reese ${ }^{5}$, Gholson J. Lyon ${ }^{1,2,3 *}$

3 ' ${ }^{1}$ Stanley Institute for Cognitive Genomics, One Bungtown Road, Cold Spring Harbor Laboratory, NY, USA, $11724 ;{ }^{2}$ Stony Brook University, 100 Nicolls Rd, Stony Brook, NY, USA, 11794; ${ }^{3}$ Department of Biomedical Informatics, University of Utah, Salt Lake City, UT, USA, 84112; ${ }^{4}$ Utah Foundation for Biomedical Research, E 3300 S, Salt Lake City, UT, USA, 84106; ${ }^{5}$ Omicia Inc., 2200 Powell St., Emeryville, CA, USA, 94608;

${ }^{6}$ AssureRx Health, Inc., 6030 S. Mason-Montgomery Road, Mason, Ohio 45040

7 * Correspondence: Gholson J. Lyon

8 Email: GholsonJLyon@gmail.com

9 Introduction

10 Deep brain stimulation (DBS) has emerged as a relatively safe and reversible neurosurgical technique that can be used in the clinical treatment of traditionally treatment resistant psychiatric disorders. DBS enables the adjustable and stable electrical stimulation of targeted brain structures. A recent paper by Höflich et $\mathrm{al}^{1}$ notes variability in treatment outcomes for DBS patients, which is likely due to variable responses to differences in targeted stimulation regions and in post-operative stimulation parameters. Both sources of variation, the authors note, will effect the stimulation of different brain tissue fibers having different anatomical and functional connections. Furthermore, the authors suggest that not every target will be suitable for every person, as there exists a large degree of inter-individual variability of brain region activation during a reward task in healthy volunteers, and suggest that future work could (and should) focus on developing surgical plans based on individual-specific activations, functional connectivity and/or tractography. This work exemplifies the large degree of clinically relevant biological variability that exists in terms of individual clinical characteristics.

Ongoing clinical trials testing the "Effectiveness of Deep Brain Stimulation for Treating People With Treatment Resistant Obsessive-Compulsive Disorder"- detail the below exclusion criteria:

- current or past psychotic disorder,

- a clinical history of bipolar mood disorder, and/or

- an inability to control suicide attempts, imminent risk of suicide in the investigator's judgment, or a history of serious suicidal behavior, which is defined using the Columbia-Suicide Severity Rating Scale (C-SSRS) as either: one or more actual suicide attempts in the 3 years before study entry with the lethality rated at 3 or higher, or one or more interrupted suicide attempts with a potential lethality judged to result in serious injury or death.

These study criteria exclude the most severe cases of OCD, as many people with severe OCD also have

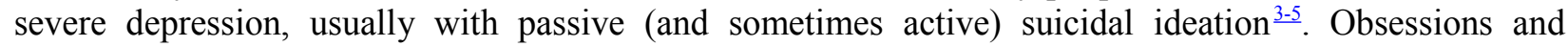
compulsions can be quite severe, with very poor insight, sometimes to a delusional or psychotic degree, and there can also be co-occurring psychoses in any individual. Each person is to some degree unique in his or her psychiatric presentation, and a tailored evaluation schema could prove more effective in clinical treatment. Due in part to these above hurdles, there are few detailed descriptions of the efficacy of DBS for OCD, with the number of published case studies on the efficacy of DBS for OCD covering upwards of $\sim 100$ people $\frac{6-21}{\text {. }}$.

An explosive growth in exome and whole genome sequencing (WGS) ${ }^{22}$ has occurred in parallel to the emergence of DBS for OCD, led in part by dramatic cost reductions. This in turn has given medical practitioners an efficient and comprehensive means to medically assess coding and non-coding regions of the genome, leading to much promise in terms of assessing and treating human disease. In our own efforts to push forward the field of precision medicine, we report here one effort to integrate the areas of clinical neuropsychiatry, brain machine interfaces and personal genomics in the individualized care of one person. We evaluate and treat an individual with DBS for treatment refractory OCD, gauge the feasibility and usefulness of the medical integration of genetic data stemming from whole genome sequencing, and search for rare variants that might alter the course of medical care for this person. As mentioned above, 
there have been relatively few reports on studies detailing the effective application of DBS for OCD; we report here one such study.

\section{Methods}

51

52

53

54

55

56

57

58

59

60

61

62

63

\section{Ethics compliance}

Research was carried out in compliance with the Helsinki Declaration. The corresponding author (GJL) conducted all clinical evaluations and he is an adult psychiatry and child/adolescent psychiatry diplomate of the American Board of Psychiatry and Neurology. GJL obtained IRB approval \#00038522 at the University of Utah in 2009-2010 to evaluate candidates for surgical implantation of the Medtronic Reclaim $^{\circledR}$ DBS Therapy for OCD, approved under a Humanitarian Device Exemption (HDE) for people with chronic, severe, treatment-resistant $\mathrm{OCD}^{23}$. The interdisciplinary treatment team consisted of one psychiatrist (GJL), one neurologist and one neurosurgeon. Implantation ultimately occurred on a clinical basis at another site. Written consent was obtained for phenotyping and whole genome sequencing through Protocol \#100 at the Utah Foundation for Biomedical Research, approved by the Independent Investigational Review Board, Inc. Informed and written consent was also obtained using the Illumina Clinical Genome Sequencing test consent form, which is a clinical test ordered by the treating physician, G.J.L.

\section{Evaluation and recruitment for DBS for treatment-refractory OCD}

GJL received training regarding DBS for OCD at a meeting hosted by Medtronic in Minneapolis, Minnesota, in September 2009. The same author attended a Tourette Syndrome Association meeting on DBS for Tourette Syndrome, Miami, Florida, in December 2009. Approximately ten candidates were evaluated over a one-year period in 2010 . The individual discussed herein received deep brain stimulation surgery at another site, and then returned for follow-up with GJL. Another psychiatrist, author RR, provided ongoing consultation throughout the course of this study. Although other candidates have since returned for follow-up (with GJL), no others have been surgically treated.

\section{CLIA WGS and the Management of Results from sequencing data}

\section{CLIA WGS using the Illumina Individual Genome Sequencing test}

Whole genome sequencing was ordered on this individual as part of our ongoing effort to implement precision medicine in the diagnosis, treatment, and preventive care for individuals. His genome was sequenced in the Illumina Clinical Services Laboratory (CLIA-certified, CAP-accredited) as part of the TruSight Individual Genome Sequencing (IGS) test, a whole-genome sequencing service using Illumina's short- read sequencing technology ${ }^{24}$ (Fig. 2). Although clinical genome sequencing was ordered by GJL on a clinical basis (thus not requiring IRB approval), the clinical phenotyping and collection of blood and saliva for other research purposes was approved by the Institutional Review Board (iIRB) (Plantation, Florida) as part of a study protocol at the Utah Foundation for Biomedical Research (UFBR). Consistent with laboratory-developed tests, WGS has not been cleared or approved by the U.S. Food and Drug Administration ${ }^{25}$. The entire procedure included barcoded sample tracking of the blood collected by GJL from this person, followed by DNA isolation and sequencing in the Illumina CLIA lab. Data statistics are summarized in Supplemental Fig. S1.

\section{WGS data analysis and variant prioritization}

For the bioinformatics analyses, Illumina utilized the internal assembler and variant caller CASAVA (short for Consensus Assessment of Sequence And VAriation). Reads were mapped to the Genome Reference Consortium assembly GRCh37. Data for sequenced and assembled genomes was provided on one hard drive, formatted with the NTFS file system and encrypted using the open source cross platform TrueCrypt software (www.truecrypt.org) and the Advanced Encryption Standard (AES) algorithm (Federal Information Processing Standards Publication 197). 
93 Genotyping array data was generated in parallel of the CLIA whole genome sequencing, using the 94 Illumina HumanOmni2.5-8 bead chip. The encrypted hard drive contains several files, including a 95 "genotyping folder" within which there is a genotyping report in a text-based tab-delimited format (see 96 Supplemental File S1). See Supplemental File 11 for more details on the genotyping array data.

97 Insertions, deletions and structural alterations are not validated variant types in the Illumina Clinical 98 Services Laboratory. Insertions and deletions provided in the gVCF file are for investigative or research 99 purposes only. A medical report and the raw genomic data were provided back to the ordering physician 100 (GJL) on an encrypted hard drive as part of the Illumina Understand your Genome Symposium, held in 101 October 2012, which included the clinical evaluation of 344 genes (see Supplemental File S2 and S3) ${ }^{26}$.

102 To perform more comprehensive downstream analyses using a greater portion of the genomic data, all of 103 the variants that were detected by the Illumina CLIA WGS pipeline were imported and analyzed within 104 the Omicia Opal web-based clinical genome interpretation platform (Fig. 2, Supplemental Fig. S5), 105 version 1.5. $0^{27}$. The Omicia system annotates variants and allows for the identification and prioritization 106 of potentially deleterious alleles. Omicia Scores, which are computationally derived estimates of deleteriousness, were calculated by using a decision-tree based algorithm, which takes as input the Polyphen, SIFT, MutationTaster and PhyloP score(s), and derives an integrative score between 0 and 1. Receiver operating characteristic (ROC) curves are plotted for that score based on annotations from HGMD. For further details on the method and the program see the Supplemental File S11 and www.omicia.com. The AssureRx Health, Inc. annotation and analysis pipeline was used to further annotate variants (see Supplemental File S11 for more detailed methods).

113 We also applied a recently published method, ERDS (Estimation by Read Depth with SNVs) version 114 1.06.04 $4^{\frac{28}{2}}$, in combination with genotyping array data, to generate a set of CNV calls. ERDS starts from 115 read depth information inferred from BAM files, but also integrates other information including paired 116 end mapping and soft-clip signature, to call CNVs sensitively and accurately. We collected deletions and 117 duplications that were $>200 \mathrm{~kb}$ in length, with confidence scores of $>300$. CNVs that were detected by the 118 ERDS method were visually inspected by importing and visualizing the read alignment data in the Golden 119 Helix Genome Browser, version 1.1.1. CNVs were also independently called from Illumina 120 HumanOmni2.5-8v1 genotyping array data. Array intensities were imported and analyzed within the 121 Illumina GenomeStudio software suite, version 1.9.4. LogR values were exported from GenomeStudio 122 and imported into Golden Helix SVS, version 7.7.5. A Copy Number Analysis Method (CNAM) optimal 123 segmentation algorithm was used to generate a list of putative CNVs, which was then restricted to include 124 only CNVs that were $>200 \mathrm{~kb}$ in length with average segment $\operatorname{LogR}$ values of $>0.15$ and $<-0.15$ for 125 duplications and deletions, respectively. LogR and covariate values were plotted and visually inspected at 126 all genomic locations where the CNAM method detected a CNV. CNVs that were simultaneously 127 detected by both methods (ERDS and CNAM) were considered to be highly confident CNVs. Highly 128 confident CNVs were, again, visually inspected within Golden Helix Genome Browser to further 129 eliminate any artefactual CNV calls.

\section{Managing sequencing results}

131 There are multiple steps involved in the management of clinical test results, beginning with bar-coded 132 tracking of orders and the return of results to the clinician's office from the outside CLIA-certified testing 133 facility. The results are transferred to the clinician, who reviews, signs, and interprets the results and 134 incorporates them into the medical health record. The patient is notified, and needed follow-up is 135 arranged.

136 In an ongoing effort to develop ways to incorporate genomic data into clinical EHR, we also collaborated 137 with the Sequence Ontology Group to convert the data into the GVFclin format (see Supplemental File 138 S12). The Genome variant format (GVF), which uses Sequence Ontology to describe genome variation ${ }^{29}$, 139 has been extended for use in clinical applications. This extended file format, called GVFClin ${ }^{30}$, adds the 
140 necessary attributes to support Health Level 7 compatible data for clinical variants. The GVF format 141 represents genome annotations for clinical applications using existing EHR standards as defined by the 142 international standards consortium: Health Level 7. Thus, GVFclin can describe the information that 143 defines genetic tests, allowing seamless incorporation of genomic data into pre-existing EHR systems.

\section{Results}

\section{5}

146

147

148

149

150

151

152

153

154

155

156

157

158

159

160

161

162

163

164

165

166

167

168

169

170

171

172

173

174

\section{5}

176

177

178

179

180

181

182

183

184

185

186

\section{Pertinent clinical symptoms and treatment}

A 37-year old man and U.S. veteran (here named with pseudonymous initials M.A.) was evaluated by GJL in 2010 for severe, treatment-refractory obsessive compulsive disorder (OCD), which is an illness that can be quite debilitating ${ }^{31}$. M.A. had a lifelong history of severe obsessions and compulsions, including contamination fears, scrupulosity, and the fear of harming others, with much milder symptoms in childhood that got much worse in his early 20's. His Yale-Brown Obsessive Compulsive Scale

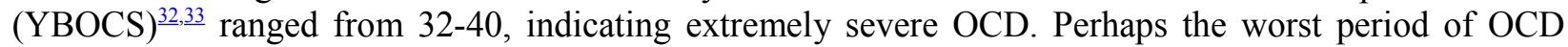
included a 5-day, near continuous, period of tapping on his computer keyboard as a compulsion to prevent harm from occurring to his family members. M.A. had suffered throughout his life from significant periods of depression with suicidal ideation, and he had attempted suicide at least three times. His prior psychiatric history also includes episodes of paranoia relating to anxieties from his OCD, and he continues to be treated with biweekly injections of risperidone. His Global Assessment of Functioning (GAF) typically ranged from 5-15 on a 100 point scale.

His treatment history included over 15 years of multiple medication trials, including clomipramine and multiple SSRIs at high doses, including fluoxetine at $80 \mathrm{mg}$ by mouth daily, along with several attempts with outpatient exposure and ritual prevention (ERP) therapy ${ }^{34}$. M.A. inquired and was evaluated by GJL at the University of Utah and then at two other centers independently offering deep brain stimulation for OCD. One of these centers required (as a condition for eligibility for an ongoing clinical trial) a two-week inpatient hospitalization with intensive ERP, which subsequently occurred and was documented as improving his YBOCS score to 24 at discharge. He maintains that he actually experienced no improvement during that hospitalization, but rather told the therapists what they wanted to hear, as they were "trying so hard". See the Supplemental File S11 for other clinical details.

The teams at the University of Utah and two other centers declined to perform surgery due to his prior history of severe depression, suicide attempts and possible psychoses with paranoia. Through substantial persistence of M.A. and his family members, a psychiatrist and neurosurgeon at a fourth center decided that he was an appropriate candidate for surgical implantation of the Medtronic Reclaim ${ }^{\circledR}$ DBS Therapy device for OCD, approved under a Humanitarian Device Exemption (HDE) for people with chronic, severe, treatment-resistant $\mathrm{OCD}^{23}$, and he was implanted in January of 2011 (Fig. 1). The device targets the nucleus accumbens / anterior limb of the internal capsule (ALIC). A detailed account of the surgical procedure can be found in the Supplemental File 11.

\section{Clinical results for DBS for treatment-refractory OCD}

After healing for one month, the implanted device (equipped with the Kinetra Model 7428 Neurostimulator) was activated on February 14, 2011, with extensive programming by an outpatient psychiatrist, with bilateral stimulation of the ALIC. Final settings were case positive, contact 1 negative on the left side at $2.0 \mathrm{~V}$, frequency $130 \mathrm{~Hz}$, and pulse width $210 \mathrm{usec}$, and case positive, contact 5 negative on the right side with identical settings.

Over the next few months, his voltage was increased monthly in increments of $0.2-0.5 \mathrm{~V}$ by an outpatient psychiatrist. He returned to one of the author's (GJL) for psychiatric treatment in July 2011, at which time his voltage was set at $4.5 \mathrm{~V}$ bilaterally. His depression had immediately improved after the surgery, along with many of his most irrational obsessions, but his YBOCS score still remained in the 35-38 range. From July 2011-December 2011, his voltage was increased bilaterally on a monthly basis in increments of $0.2 \mathrm{~V}$, with steady improvement with his OCD until his battery started to lose charge by December 2011. This 
caused him considerable anxiety, prompting him to turn off his battery in order to "save battery life", which unfortunately led to a complete relapse to his baseline state in a 24 hour period, which was reversed when he turned the battery back on. The battery was surgically replaced with a rechargeable Activa $R C$ neurostimulator battery in January 2012, and the voltage has been increased monthly in $0.1-0.2 \mathrm{~V}$ increments until the present time (May 2013).

At every visit, M.A. has reported improvements, with reductions of his obsessions and compulsions, marked by a steady decline in his YBOCS score (Fig. 3). M.A. has started to participate in many activities that he had never previously been able to engage in. This includes: exercising (losing 50 pounds in two years) and volunteering at the church and other organizations, but not yet able to work in any paid capacity. M.A. also started dating and recently got married, highlighting his improvement in daily functioning, with a GAF score ranging now from 40-50. New issues that M.A. reports are consistent tenesmus, occasional diarrhea (which he can now tolerate despite prior contamination obsessions) and improved vision (going from 20/135 to 20/40 vision, as documented by his optometrist), with him no longer needing to wear glasses. It is unknown whether the DBS implant has contributed to any of these issues. Attempts to add fluoxetine at $80 \mathrm{mg}$ by mouth daily for two months to augment any efficacy from the DBS and ERP were unsuccessful, mainly due to no discernible benefit and prominent sexual side effects. M.A. still receives an injection of $37.5 \mathrm{mg}$ risperidone every two weeks for his past history of psychoses; otherwise, he no longer takes any other medications. There has not been any exacerbation of psychoses in this individual during the two years of treatment with DBS.

\section{CLIA certified WGS results}

\section{Illumina WGS clinical evaluations}

The Illumina WGS clinical evaluation included manual annotation of 344 genes (see Supplemental Fig. S2, Supplemental File S2 and S3), which led to the following conclusion:

"No pathogenic or likely pathogenic variants were found in the 344 genes evaluated that are expected to be clinically significant for the patient. The coverage for these 344 genes is at least 99\%. Therefore, significant variants could exist that are not detected with this test."

The clinical evaluation did, however, identify M.A. as a carrier for a variant (c.734G $>$ A ,p.Arg245Gln) in PHYH, which has been associated in the autosomal recessive or compound heterozygote states with Refsum disease, which is an inherited condition that can lead to vision loss, anosmia, and a variety of other signs and symptoms ${ }^{35}$. In silico prediction programs suggest little impact; however, the variant is rare with a 1000 Genomes frequency of $\sim 0.18 \%$. In this regard, it is worth noting that M.A. has always had poor night vision and enlarged pupils, and, as a result of this genetic finding, we met with M.A.'s treatment team at his Veteran's Affair's (V.A.) medical center and learned that he had recently been diagnosed with bilateral cataracts, enlarged pupils, and vision loss. We also learned that M.A.'s mother and maternal grandfather have a history of enlarged pupils with poor vision, and we are currently following up whether this might be related in any way to this particular variant and Refsum disease.

\section{Disease variant discovery}

Further downstream analyses (Fig 2.) identified and prioritized several other potentially clinically relevant variants. Variants that were imported into the Omicia Opal system were filtered to include those that had a high likelihood of being damaging (as defined by an Omicia score $>0.7$ ) and those that have supporting Online Mendelian Inheritance in Man (OMIM; an online database of human genetics and genetic disorders) evidence. We chose to filter based on an Omicia Score of $>0.7$ as this value derives a slightly more inclusive list of variants which still cannot be dismissed, but for which we have additional corroborating evidence (i.e., Illumina Genome Network (IGN) validation and annotation). These prioritized variants were further annotated and evaluated by the AssureRx Health, Inc. annotation and analysis pipeline. Prioritized variants are shown in Supplemental File S4 and Supplemental Fig. S3. A 
233 longer list of variants, which were required only to have supporting evidence within the OMIM database,

234 is shown in Supplemental File S5. We highlight here some of the findings:

235 M.A. was found to be a heterozygote for a p.Val66Met change in $B D N F$, which encodes a protein that is a 236 member of the nerve growth factor (NGF) family. The protein is induced by cortical neurons, and is 237 deemed necessary for the survival of striatal neurons in the brain. In drug naïve patients, BDNF serum 238 levels were found to be significantly decreased in OCD patients when compared to controls $(36.90 \pm 6.42$ $239 \mathrm{ng} / \mathrm{ml}$ versus $41.59 \pm 7.82 \mathrm{ng} / \mathrm{ml} ; \mathrm{p}=0.043)^{\frac{36}{6}}$, suggesting a link between this protein and OCD. 240 Moreover, a study including 164 proband-parent trios with obsessive-compulsive disorder ${ }^{37}$ uncovered 241 significant evidence of an association between OCD and all of the BDNF markers that were tested, 242 including the exact variant found here in this person, p.Val66Met. This particular variant has been further studied in a sample of 94 nuclear families $\frac{38}{}$, which included 94 probands with schizophrenia-spectrum disorders and 282 family members. The results of this study suggest that the p.Val66Met polymorphism may play a role in the phenotype of psychosis. Similar anxiety-related behavioral phenotypes have also been observed among mice and humans having the p.Val66Met variant in BDNF ${ }^{39}$. In humans, the amygdala mediates conditioned fear ${ }^{40}$, normally inhibited by 'executive centers' in medial prefrontal cortex $^{41}$. Deep brain stimulation of the pathways between medial prefrontal cortex and the amygdala increased the extinction of conditioned fear in a rat model of $\mathrm{OCD}^{42}$. Studies using functional magnetic resonance imaging (fMRI) demonstrate that humans with the p.Val66Met variant exhibit exaggerated activation of the amygdala in response to an emotional stimulus in comparison to controls lacking the variant $^{43,44}$. It is thought that this variant may influence anxiety disorders by interfering with the learning of cues that signal safety rather than threat and may also lessen efficacy of treatments that rely on extinction mechanisms, such as exposure therapy ${ }^{39}$. In this regard, it is interesting to note that this person did indeed obtain very little benefit from exposure therapy prior to surgery.

M.A heterozygously carries the p.Glu429Ala allele in MTHFR, encoding a protein that catalyzes the conversion of 5,10-methylenetetrahydrofolate to 5-methyltetrahydrofolate, a co-substrate for homocysteine remethylation to methionine, and which has been shown to confer an elevated susceptibility to psychoses. Variants in MTHFR influence susceptibility to occlusive vascular disease, neural tube defects, colon cancer and acute leukemia. Variants in this gene are associated with methylenetetrahydrofolate reductase deficiency. In addition, a meta-analysis comparing 1,211 cases of schizophrenia with 1,729 controls found that the MTHFR p.Glu429Ala allele was associated with susceptibility to schizophrenia $^{45}$ (odds ratio, $1.19 ; 95 \%$ CI, 1.07- 1.34; $\mathrm{p}=0.002$ ). According to the Venice guidelines for the assessment of cumulative evidence in genetic association studies, the MTHFR association exhibited a strong degree of epidemiologic credibility ${ }^{46}$. Pharmacogenetic studies have found a consistent association between the MTHFR p.Glu429Ala allele and metabolic disorder in adult, adolescent and children taking atypical antipsychotic drugs ${ }^{47}, 48$.

M.A. is also heterozygous for the p.Val108Met variant in catechol-O-methyltransferase (COMT), which catalyzes the transfer of a methyl group from S-adenosylmethionine to catecho- lamines, including the neurotransmitters dopamine, epinephrine, and norepinephrine. The minor allele A of this $472 \mathrm{G}>\mathrm{A}$ variant produces a valine to methionine substitution, resulting in a less thermostable COMT enzyme that exhibits a 3-fold reduction in activity. A substantial body of literature implicates this variant as possibly elevating the risk for various neuropsychiatric disorders in some Caucasian populations but not necessarily in other genetic backgrounds ${ }^{49-55}$. There is some evidence that MTHFR x COMT genotype interactions might also be occurring in M.A. to influence his neuropsychiatric status $\frac{56}{}$, and the same is true for BDNF x COMT

276 interactions $^{57}$.

278 Pharmacogenetic analyses were performed using the Omicia Opal platform. Pharmacogenetic variants were identified and prioritized by activating the "Drugs and Pharamcology" track within the Opal system and by requiring these variants to have prior evidence within any one of several supporting databases (i.e., OMIM, HGMD, PharmGKB, LSDB and GWAS). Prioritized variants are shown in Supplemental File S6 
282 and Supplemental Fig. S4. A longer, more inclusive list is shown in Supplemental File S7; variants in this 283 file are only required to be detected by the "Drugs and Pharmacology" track in Opal. Variants within 284 Supplemental File S6/S7 were further annotated and analyzed by the AssureRx Health, Inc. pipeline (see 285 Supplemental File S8). Below, we highlight pharmacogenetic variants found to be informative in terms of 286 future medication choices for M.A.

287 M.A. is heterozygous for a c.19G>A p.Asp7Asn allele in ChAT, encoding choline O-acetyltransferase, 288 which synthesizes the neuro-transmitter acetylcholine (Supplemental Fig. S5). This particular variant 289 (rs1880676) is significantly associated with both risk for schizophrenia in Caucasians $(\mathrm{P}=0.002)$, 290 olanzapine response $(\mathrm{P}=0.04)$ and for other psychopathology $(\mathrm{P}=0.03)^{\frac{58}{2}}$. Allele $\mathrm{A}$ is associated with 291 increased response to olanzapine in people with schizophrenia as compared to allele $\mathrm{G}$. This association 292 was nominally significant $(\mathrm{p}=0.04)$ in the Spanish cohort $\underline{\underline{58}}$.

293

294

295

296

297

298

299

300

301

302

303

304

305

306

M.A. is homozygous for a p.Ile359Leu change in CYP2C9, and this variant has been linked to a reduction in the enzymatic activity of CYP2C $9^{59}$. CYP2C9 encodes a member of the cytochrome P450 superfamily of enzymes. Cytochrome $\mathrm{P} 450$ proteins are mono-oxygenases, which catalyze many reactions associated with drug metabolism as well as reactions associated with the synthesis of cholesterol, steroids and other lipids ${ }^{60}$. CYP2C9 localizes to the endoplasmic reticulum and its expression is induced by rifampin. CYP2C9 is known to metabolize xenobiotics, including phenytoin, tolbutamide, ibuprofen as well as Swarfarin. Studies identifying individuals who are poor metabolizers of phenytoin and tolbutamide suggest associations between metabolism and polymorphisms found within this gene. $C Y P 2 C 9$ is located within a

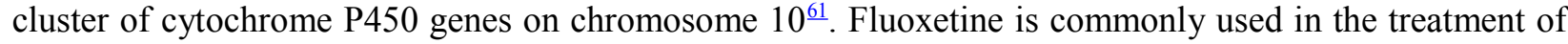
OCD; it has been shown to be as effective as clomipramine and causes less side effects ${ }^{62,63}$. CYP2C9 acts

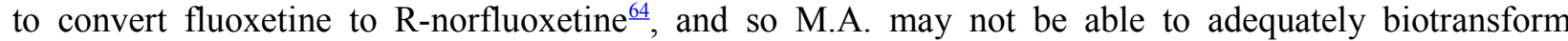
fluoxetine ${ }^{65}$. However, CYP2C9 does not play a rate-limiting role for other SSRIs or clomipramine. In his own treatment experience, M.A. had no response to an $80 \mathrm{mg}$ daily dose of fluoxetine, although he did experience sexual side effects at that dosage.

307 The protein encoded by $D P Y D$ is a pyrimidine catabolic enzyme and it acts as the initial and rate-limiting 308 factor in uracil and thymidine catabolism pathways. M.A. was found to be a carrier of two variants in this 309 gene, p.Ile543 Val and p.Arg29Cys, for which he is a heterozygote and homozygote, respectively. Variants 310 within DPYD result in dihydropyrimidine dehydrogenase deficiency, an error in pyrimidine metabolism 311 associated with thymine-uraciluria and an increased risk of toxicity in cancer patients receiving 5312 fluorouracil chemotherapy. Two transcript variants encoding different isoforms have been described for $313 D P Y D^{66,67}$.

314 M.A. is heterozygous both for a c.590G >A p.Arg197Gln allele (rs1799930) and a c.803G >A p.Arg268Lys 315 allele (rs1208) in NAT2, encoding an enzyme that functions to both activate and deactivate arylamine and

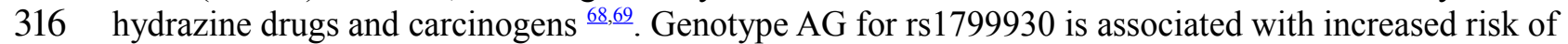

317 toxic liver disease in people with tuberculosis when treated with ethambutol, isoniazid, pyrazinamide and 318 rifampin as compared to genotype GG. Allele G for rs1208 is not associated with risk of hypersensitivity 319 when treated with sulfamethoxazole and trimethoprim in people with infection.

\section{Copy number variants}

321 ERDS identified 60 putative CNVs, all of which were visually inspected within the Golden Helix Genome 322 Browser. Many of the CNVs detected by the ERDS method were found to be located within chromosomal 323 boundary regions and were determined to be false positives due to highly variable read depth in these regions. The CNAM method detected 35 putative CNVs, which were visually inspected by plotting the LogR and covariate values in Golden Helix SVS. Only six CNVs were simultaneously detected by both the ERDS and CNAM methods, and were visually inspected as further confirmation to be included among the set of highly confident CNVs. High-confidence CNVs are shown in Supplemental File S9. To our knowledge, these CNVs have not been previously associated in any way with M.A.'s disease phenotype, but we are archiving these results for future analysis as knowledge of CNVs and disease associations 
expands.

\section{Return of results}

332 A board-certified genetic counselor was consulted by GJL prior to returning results, and all therapy and 333 counseling was provided by GJL. Although we believe in archiving and managing all genetic results and 334 not just a small subset of genes, we did analyze the 57 genes that are currently recommended for "return 335 of results" by the American College of Medical Genetics ${ }^{70}$. These results are shown in Supplemental File 336 S10, and one of us (GJL) met with M.A. to go over the results with him, along with adding some of the 337 findings into his paper-based medical record. Lastly, we did contact the physicians and other officials at 338 the U.S. Veterans Affairs office to offer to incorporate these data into the electronic medical record for 339 M.A. at the VA, but we were informed that the VistA health information system (HIS) ${ }^{71-74}$ does not 340 currently have the capability to incorporate any genomic variant data.

\section{Discussion}

\section{DBS for treatment-refractory OCD}

Deep brain stimulation for M.A.'s treatment refractory OCD has provided a quantifiable and significant improvement in the management of his symptoms (Fig. 3). M.A. has regained a quality of life that he had previously not experienced in over 15 years, which is highlighted by him participating in regular exercise, working as a volunteer in his local church, dating, and eventually getting married, all of which act to illustrate a dramatic improvement in his daily functioning since receiving DBS treatment for his OCD.

One significant aspect of this study is the rechargeable, and hence depleteable, nature of the Activa RC neurostimulator battery, which serves to illustrate the efficacy of DBS for OCD for this individual. On one such illustrative occasion, M.A. forgot to take the recharging device on a four-day weekend trip. Once his battery was depleted, all of his symptoms gradually returned to their full level over a $\sim 24$ hour period, including severe OCD, depression and suicidality. Since that episode, M.A. always takes his recharging device with him on extended trips, but there have been other such instances in which his battery has become depleted for several hours, with the noticeable and intense return of his OCD symptoms and the cessation of his tenesmus. The electrical stimulation is having a demonstrable effect on his OCD, and these data are complementary to other data-sets involving turning DBS devices off for one week at a time ${ }^{19}$.

There are many ethical and regulatory issues relating to deep brain stimulation that have been discussed elsewhere ${ }^{75-81}$, and we report here our one positive experience, made possible when the US Food and Drug Administration granted a Humanitarian Device Exemption (HDE) to allow clinicians to use this intervention. The rechargeable nature of the new battery has been reassuring to M.A., as he is able to exert self-control over his battery life, whereas he previously had no control with the original "single-use" battery that must be replaced when the battery depletes (usually at least once annually). We assume that other persons treated with DBS for OCD will likely also start receiving rechargeable batteries. In this regard, it is worth noting that the recent development of an injectable class of cellular-scale optoelectronics paves the way for implanted wireless devices $\frac{82}{2}$, and we fully expect that there will be more brain-machine neural interfaces used in humans in the future $\frac{83-87}{}$.

\section{Clinical WGS}

There are still many challenges in showing how any one mutation can contribute toward a clear phenotype, particularly in the context of genetic background and possible environmental influences $\frac{88}{\text {. }}$ Bioinformatics confounders, such as poor data quality ${ }^{89}$, sequence inaccuracy, and variation introduced by different methodological approaches ${ }^{90}$ can further complicate biological and genetic inferences. Although the variants discussed in the results section of our study have been previously associated with mental

374 disease, we caution that the data presented are not sufficient to implicate any particular mutation as being 
necessary or sufficient to lead to the described phenotype, particularly given that mental illness results from a complex interaction of any human with their surrounding environment and social support structures. The genetic architecture of most neuropsychiatric illness is still largely undefined and controversial $\stackrel{91-94}{2}$. We provide our study as a cautionary one: WGS cannot act as a diagnostic and prognostic panacea for neuropsychiatric disorders, but instead could act to elucidate risk factors for psychiatric disease and pharmacogenetic variants that can inform future medication treatments.

During our study, we found that M.A. carries at least three alleles that have been associated with neuropsychiatric phenotypes, including variants in $B D N F, M T H F R$, and ChAT (Table 1). And, although we have discovered informative phamacogenetic variants in this person, these discoveries have not led to the immediate alteration of this person's medication schema. We have archived these discoveries, as described below, and expect that these variants will be useful over the course of his life-long medical care. We feel that this information is inherently valuable, as one can never predict with certainty what the future might hold, and a more complete medical profile on individual patients will facilitate more informed medical choices.

\section{Integrating WGS data into the Electronic Medical Health Record}

In the context of the incomplete, and sometimes proprietary, nature of human gene mutation databases, it is likely that analyses and medical guidance gleaned from these WGS data will differ from institution to institution. It is therefor important that people be given the opportunity, like with many other traditional medical tests, to obtain "second opinions". For this to be possible, one must accurately describe the contents of short-read sequencing data in terms of the existing electronic medical health standards, so that these data can be incorporated into an electronic medical health record. Accurately describing the contents of next generation sequencing (NGS) results is particularly critical for clinical analysis of genomic data. However, genomics and medicine use different, often incompatible terminologies and standards to describe sequence variants and their functional effects. In our efforts to treat this one person with severe mental illness, we have implemented the GVFclin format for the variants that were discovered during the sequencing of his whole genome (see Supplemental File S12). We hope to eventually incorporate his genetic data into his electronic health record, if and when the VistA health information system (HIS) $)^{\frac{71-74}{1}}$ is upgraded to allow entry of such data. We did already counsel M.A. regarding several genetic variants that may be clinically relevant to predisposing him to his psychiatric disorder ${ }^{95}$.

\section{Returning genetic results}

There is considerable controversy in the field of medical genetics concerning the extent of return of genetic results to people, particularly in the context of "secondary", "unrelated", "unanticipated" or

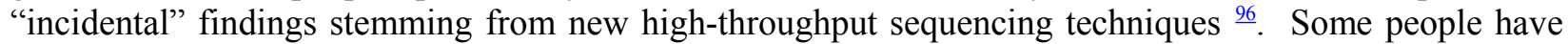
concerns regarding the clinical utility of much of the data, and in response have advocated for selectively restricting the returnable medical content. One such set of recommendations has been provided by the American College of Medical Genetics which recently released guidelines in which they recommended the "return of secondary findings" for 57 genes, without detailed guidance for the rest of the genome ${ }^{97}$. These types of recommendations take a more paternalistic approach in returning test results to people, and generally involve a deciding body of people that can range in size from a single medical practitioner to a committee of experts. We believe that anyone should be able to access and manage their own genome data $^{\frac{98}{}}$, just like how anyone should be able to own and manage their medical and radiology test results ${ }^{99}$, particularly if the testing is performed with suitably appropriate clinical standards in place, i.e. CLIA in America ${ }^{100,101}$. In this regard, we found by means of WGS that M.A carries a variant in $P H Y H$, this revelation ended up improving his care despite not being related in any known or direct way to his psychiatric disorder, which is the main focus of this study. As stated in our Results section, M.A. has been diagnosed with bilateral cataracts and has been counseled in ways to reduce further damage to and deterioration of his vision. 


\section{Conclusions}

423 One can learn a substantial amount from detailed study of particular individuals (for just a small sampling, see $^{102-109}$ ), and we believe that we are entering an era of precision medicine in which we can learn from and collect substantial data on informative individual cases. Incorporating insights from a range of scientific and clinical disciplines into the study and treatment of any one person is therefore beginning to emerge as a tractable, and more holistic, approach, and we document here what we believe to be the first integration of deep brain stimulation and whole genome sequencing for precision medicine in the evaluation, treatment and preventive care for one severely mentally ill individual, M.A. We have shown that DBS has been successful in aiding in the care and beneficial clinical outcome of his treatment refractory OCD, and we have also demonstrated that it is indeed feasible, given current technologies, to incorporate health information from WGS into the clinical care of one person with severe mental illness, including with the return of these health information to him directly. On a comparative level, deep brain stimulation has thus far been a more direct and effective intervention for his mental illness than anything discovered from his whole genome sequencing. Despite this, health information stemming from these WGS data was nevertheless immediately useful in the care of this person, as a variant associated with his ophthalmologic phenotype did indeed inform and enrich his care, and we expect that these data will continue to inform his care as our understandings of human biology and the genetic architecture of disease improves. Of course, the genomic data would have been more helpful if obtained much earlier in his medical course, as it could have provided guidance on which medications to avoid or to provide in increased doses.

\section{Contributions}

GJL conceived of the project, conducted psychiatric evaluations, provided clinical care, analyzed data, supervised other data analyses, and wrote the first draft of the manuscript. JO edited the manuscript extensively and analyzed the data. HF, GH, ESK and MGR analyzed and interpreted the whole genome data. RR leads the Utah Foundation for Biomedical Research and assisted with clinical phenotyping. All authors read, commented on, and approved the final manuscript.

\section{Conflicts of Interest}

The corresponding author (GJL) has had informal discussions with representatives from Medtronic, Illumina, and Omicia, Inc., but he has not had any formal consulting role, nor received financial compensation or grants from these or any other for-profit companies performing deep brain stimulation, DNA collection or sequencing. GJL does not hold any patents, and he is unaware of any conflicts of interest on his part. Revenue earned by GJL from providing medical care in Utah is currently donated to the Utah Foundation for Biomedical Research for genetics research. ESK and MGR are co-founders and officers of Omicia, Inc., and GH is an employee of Assure Rx, Inc. All authors read and approved of the content in the manuscript.

\section{Acknowledgements}

457 We thank the many doctors and other caregivers who have worked with M.A, including Drs. Paul House, Ziad Nahas and Istvan Takacs. GJL thanks Kenyon Fausett (at Medtronic) and Lauren Schrock (at University of Utah) for helping train him to perform DBS programming. M.A. and his family have been extraordinarily cooperative throughout the course of treatment. We also thank Tina Hambuch, Erica Ramos, Dawn Barry and others at Illumina for helping to develop the TruSight Individual Genome Sequencing (IGS) test, a whole-genome sequencing service using Illumina's short-read sequencing technology in the CLIA-certified, CAP-accredited Illumina Clinical Services Laboratory. They provided fee-for-service whole genome sequencing in the CLIA lab at Illumina, along with generating the clinical report on 344 genes. Julianne O'Daniel graciously provided advice regarding genetic counseling, along with helping interpret findings in the 57 genes that are currently recommended for "return of results" by the American College of Medical Genetics.

\section{References}


1 Hoflich, A., Savli, M., Comasco, E., Moser, U., Novak, K., Kasper, S. \& Lanzenberger, R. Neuropsychiatric deep brain stimulation for translational neuroimaging. Neuroimage 79, 30-41, doi:http://dx.doi.org/10.1016/j.neuroimage.2013.04.065 (2013).

2 ClinicalTrials.gov Identifier: NCT00640133: Effectiveness of Deep Brain Stimulation for Treating People With Treatment Resistant Obsessive-Compulsive Disorder, <http://clinicaltrials.gov/show/NCT00640133> (2013).

3 Torres, A. R., Ramos-Cerqueira, A. T., Ferrao, Y. A., Fontenelle, L. F., do Rosario, M. C. \& Miguel, E. C. Suicidality in obsessive-compulsive disorder: prevalence and relation to symptom dimensions and comorbid conditions. J Clin Psychiatry 72, 17-26; quiz 119-120, doi:10.4088/JCP.09m05651blu (2011).

4 Alonso, P., Segalas, C., Real, E., Pertusa, A., Labad, J., Jimenez-Murcia, S., Jaurrieta, N., Bueno, B., Vallejo, J. \& Menchon, J. M. Suicide in patients treated for obsessive-compulsive disorder: a prospective follow-up study. J Affect Disord 124, 300-308, doi:10.1016/j.jad.2009.12.001 (2010).

5 Balci, V. \& Sevincok, L. Suicidal ideation in patients with obsessive-compulsive disorder. Psychiatry Res 175, 104-108, doi:10.1016/j.psychres.2009.03.012 (2010).

6 Roh, D., Chang, W. S., Chang, J. W. \& Kim, C. H. Long-term follow-up of deep brain stimulation for refractory obsessivecompulsive disorder. Psychiatry Res 200, 1067-1070, doi:10.1016/j.psychres.2012.06.018 (2012).

7 Goodman, W. K. \& Alterman, R. L. Deep brain stimulation for intractable psychiatric disorders. Annu Rev Med 63, 511-524, doi:10.1146/annurev-med-052209-100401 (2012).

8 Blomstedt, P., Sjoberg, R. L., Hansson, M., Bodlund, O. \& Hariz, M. I. Deep Brain Stimulation in the Treatment of ObsessiveCompulsive Disorder. World Neurosurg, doi:10.1016/j.wneu.2012.10.006 (2012).

9 Burdick, A. P. \& Foote, K. D. Advancing deep brain stimulation for obsessive-compulsive disorder. Expert Rev Neurother 11, 341-344, doi:10.1586/ern.11.20 (2011).

10 Mian, M. K., Campos, M., Sheth, S. A. \& Eskandar, E. N. Deep brain stimulation for obsessive-compulsive disorder: past, present, and future. Neurosurg Focus 29, E10, doi:10.3171/2010.4.FOCUS10107 (2010).

11 Haynes, W. I. \& Mallet, L. High-frequency stimulation of deep brain structures in obsessive-compulsive disorder: the search for a valid circuit. Eur J Neurosci 32, 1118-1127, doi:10.1111/j.1460-9568.2010.07418.x (2010).

12 Goodman, W. K., Foote, K. D., Greenberg, B. D., Ricciuti, N., Bauer, R., Ward, H., Shapira, N. A., Wu, S. S., Hill, C. L., Rasmussen, S. A. \& Okun, M. S. Deep brain stimulation for intractable obsessive compulsive disorder: pilot study using a blinded, staggered-onset design. Biol Psychiatry 67, 535-542, doi:10.1016/j.biopsych.2009.11.028 (2010).

13 Denys, D., Mantione, M., Figee, M., van den Munckhof, P., Koerselman, F., Westenberg, H., Bosch, A. \& Schuurman, R. Deep brain stimulation of the nucleus accumbens for treatment-refractory obsessive-compulsive disorder. Arch Gen Psychiatry 67, 1061-1068, doi:10.1001/archgenpsychiatry.2010.122 (2010).

14 Komotar, R. J., Hanft, S. J. \& Connolly, E. S., Jr. Deep brain stimulation for obsessive compulsive disorder. Neurosurgery 64, N13, doi:10.1227/01.NEU.0000349645.64376.86 (2009).

15 Jimenez-Ponce, F., Velasco-Campos, F., Castro-Farfan, G., Nicolini, H., Velasco, A. L., Salin-Pascual, R., Trejo, D. \& Criales, J. L. Preliminary study in patients with obsessive-compulsive disorder treated with electrical stimulation in the inferior thalamic peduncle. Neurosurgery 65, 203-209; discussion 209, doi:10.1227/01.NEU.0000345938.39199.90 (2009).

16 Denys, D. \& Mantione, M. Deep brain stimulation in obsessive-compulsive disorder. Prog Brain Res 175, 419-427, doi:10.1016/S0079-6123(09)17527-1 (2009).

17 Burdick, A., Goodman, W. K. \& Foote, K. D. Deep brain stimulation for refractory obsessive-compulsive disorder. Front Biosci 14, 1880-1890 (2009).

18 Shah, D. B., Pesiridou, A., Baltuch, G. H., Malone, D. A. \& O'Reardon, J. P. Functional neurosurgery in the treatment of severe obsessive compulsive disorder and major depression: overview of disease circuits and therapeutic targeting for the clinician. Psychiatry (Edgmont) 5, 24-33 (2008).

19 Figee, M., Luigjes, J., Smolders, R., Valencia-Alfonso, C. E., van Wingen, G., de Kwaasteniet, B., Mantione, M., Ooms, P., de Koning, P., Vulink, N., Levar, N., Droge, L., van den Munckhof, P., Schuurman, P. R., Nederveen, A., van den Brink, W., Mazaheri, A., Vink, M. \& Denys, D. Deep brain stimulation restores frontostriatal network activity in obsessive-compulsive disorder. Nat Neurosci 16, 386-387, doi:10.1038/nn.3344 (2013).

20 Lipsman, N., Gerretsen, P., Torres, C., Lozano, A. M. \& Giacobbe, P. A psychiatric primer for the functional neurosurgeon. $J$ Neurosurg Sci 56, 209-220 (2012).

21 Lipsman, N., Neimat, J. S. \& Lozano, A. M. Deep brain stimulation for treatment-refractory obsessive-compulsive disorder: the search for a valid target. Neurosurgery 61, 1-11; discussion 11-13, doi:10.1227/01.neu.0000279719.75403.f7 (2007).

22 Lyon, G. J. \& Wang, K. Identifying disease mutations in genomic medicine settings: current challenges and how to accelerate progress. Genome Med 4, 58, doi:10.1186/gm359 (2012).

23 Medtronic. $<$ http://www.medtronic.com/patients/obsessive-compulsive-disorder-ocd/getting-therapy/> (2013).

24 Individual Genome Sequencing (IGS) Test, $<$ http://www.illumina.com/clinical/illumina_clinical_laboratory.ilmn $>$ (2013).

25 Lyon, G. J. \& Segal, J. P. Practical, ethical and regulatory considerations for the evolving medical and research genomics landscape. Applied \& Translational Genomics, doi: http://dx.doi.org/10.1016/j.atg.2013.02.001, (2013).

26 Friend, S. F., Peterson, L. K., Kedl, R. M. \& Dragone, L. L. SLAP deficiency increases TCR avidity leading to altered repertoire and negative selection of cognate antigen-specific CD8+ T cells. Immunol Res 55, 116-124, doi:10.1007/s12026012-8354-y (2013).

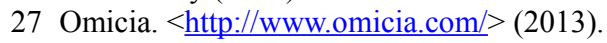

28 Zhu, M., Need, A. C., Han, Y., Ge, D., Maia, J. M., Zhu, Q., Heinzen, E. L., Cirulli, E. T., Pelak, K., He, M., Ruzzo, E. K., Gumbs, C., Singh, A., Feng, S., Shianna, K. V. \& Goldstein, D. B. Using ERDS to infer copy-number variants in highcoverage genomes. American journal of human genetics 91, 408-421, doi:10.1016/j.ajhg.2012.07.004 (2012).

29 Reese, M. G., Moore, B., Batchelor, C., Salas, F., Cunningham, F., Marth, G. T., Stein, L., Flicek, P., Yandell, M. \& Eilbeck, 
K. A standard variation file format for human genome sequences. Genome Biol 11, R88, doi:10.1186/gb-2010-11-8-r88 (2010).

30 Eilbeck, K. GVFclin, <http://www.sequenceontology.org/resources/gvfclin.html > (2013).

31 Murphy, T. W., Zine, E. E. \& Jenike, M. A. Life in rewind : the story of a young courageous man who persevered over OCD and the Harvard doctor who broke all the rules to help him. 1st edn, (William Morrow, 2009).

32 Goodman, W. K., Price, L. H., Rasmussen, S. A., Mazure, C., Fleischmann, R. L., Hill, C. L., Heninger, G. R. \& Charney, D. S. The Yale-Brown Obsessive Compulsive Scale. I. Development, use, and reliability. Arch Gen Psychiatry 46, 1006-1011 (1989).

33 Goodman, W. K., Price, L. H., Rasmussen, S. A., Mazure, C., Delgado, P., Heninger, G. R. \& Charney, D. S. The Yale-Brown Obsessive Compulsive Scale. II. Validity. Arch Gen Psychiatry 46, 1012-1016 (1989).

34 Gillihan, S. J., Williams, M. T., Malcoun, E., Yadin, E. \& Foa, E. B. Common Pitfalls in Exposure and Response Prevention (EX/RP) for OCD. J Obsessive Compuls Relat Disord 1, 251-257, doi:10.1016/j.jocrd.2012.05.002 (2012).

35 Greenberg, B. D., Malone, D. A., Friehs, G. M., Rezai, A. R., Kubu, C. S., Malloy, P. F., Salloway, S. P., Okun, M. S., Goodman, W. K. \& Rasmussen, S. A. Three-year outcomes in deep brain stimulation for highly resistant obsessivecompulsive disorder. Neuropsychopharmacology 31, 2384-2393, doi:10.1038/sj.npp.1301165 (2006).

36 Maina, G., Rosso, G., Zanardini, R., Bogetto, F., Gennarelli, M. \& Bocchio-Chiavetto, L. Serum levels of brain-derived neurotrophic factor in drug-naive obsessive-compulsive patients: a case-control study. J Affect Disord 122, 174-178, doi:10.1016/j.jad.2009.07.009 (2010).

37 Hall, D., Dhilla, A., Charalambous, A., Gogos, J. A. \& Karayiorgou, M. Sequence Variants of the Brain-Derived Neurotrophic Factor (BDNF) Gene Are Strongly Associated with Obsessive-Compulsive Disorder. American journal of human genetics $\mathbf{7 3}$, 370-376 (2003).

38 Rosa, A., Cuesta, M. J., Fatjó-Vilas, M., Peralta, V., Zarzuela, A. \& Fañanás, L. The Val66Met polymorphism of the brainderived neurotrophic factor gene is associated with risk for psychosis: Evidence from a family-based association study. American Journal of Medical Genetics Part B: Neuropsychiatric Genetics 141B, 135-138, doi:10.1002/ajmg.b.30266 (2006).

39 Soliman, F., Glatt, C. E., Bath, K. G., Levita, L., Jones, R. M., Pattwell, S. S., Jing, D., Tottenham, N., Amso, D., Somerville, L. H., Voss, H. U., Glover, G., Ballon, D. J., Liston, C., Teslovich, T., Van Kempen, T., Lee, F. S. \& Casey, B. J. A Genetic Variant BDNF Polymorphism Alters Extinction Learning in Both Mouse and Human. Science 327, 863-866, doi:10.1126/science.1181886 (2010).

40 Davis, M. The role of the amygdala in fear and anxiety. Annu Rev Neurosci 15, 353-375, doi:10.1146/annurev.ne.15.030192.002033 (1992).

41 Moscarello, J. M. \& LeDoux, J. E. Active avoidance learning requires prefrontal suppression of amygdala-mediated defensive reactions. $J$ Neurosci 33, 3815-3823, doi:10.1523/JNEUROSCI.2596-12.2013 (2013).

42 Rodriguez-Romaguera, J., Do Monte, F. H. \& Quirk, G. J. Deep brain stimulation of the ventral striatum enhances extinction of conditioned fear. Proc Natl Acad Sci US A 109, 8764-8769, doi:10.1073/pnas.1200782109 (2012).

43 Montag, C., Reuter, M., Newport, B., Elger, C. \& Weber, B. The BDNF Val66Met polymorphism affects amygdala activity in response to emotional stimuli: evidence from a genetic imaging study. Neuroimage 42, 1554-1559, doi:10.1016/j.neuroimage.2008.06.008 (2008).

44 Lau, J. Y., Goldman, D., Buzas, B., Hodgkinson, C., Leibenluft, E., Nelson, E., Sankin, L., Pine, D. S. \& Ernst, M. BDNF gene polymorphism (Val66Met) predicts amygdala and anterior hippocampus responses to emotional faces in anxious and depressed adolescents. Neuroimage 53, 952-961, doi:10.1016/j.neuroimage.2009.11.026 (2010).

45 Allen, N. C., Bagade, S., McQueen, M. B., Ioannidis, J. P. A., Kavvoura, F. K., Khoury, M. J., Tanzi, R. E. \& Bertram, L. Systematic meta-analyses and field synopsis of genetic association studies in schizophrenia: the SzGene database. Nat Genet 40, 827-834, doi:http://www.nature.com/ng/journal/v40/n7/suppinfo/ng.171_S1.html (2008).

46 Frayling, T. M. Commentary: Genetic association studies see light at the end of the tunnel. International Journal of Epidemiology 37, 133-135, doi:10.1093/ije/dym205 (2008).

47 Correll, C. U., Manu, P., Olshanskiy, V., Napolitano, B., Kane, J. M. \& Malhotra, A. K. Cardiometabolic risk of secondgeneration antipsychotic medications during first-time use in children and adolescents. Jama 302, 1765-1773, doi:10.1001/jama.2009.1549 (2009).

48 van Winkel, R., Moons, T., Peerbooms, O., Rutten, B., Peuskens, J., Claes, S., van Os, J. \& De Hert, M. MTHFR genotype and differential evolution of metabolic parameters after initiation of a second generation antipsychotic: an observational study. Int Clin Psychopharmacol 25, 270-276, doi:10.1097/YIC.0b013e32833bc60d (2010).

49 Collip, D., van Winkel, R., Peerbooms, O., Lataster, T., Thewissen, V., Lardinois, M., Drukker, M., Rutten, B. P., Van Os, J. \& Myin-Germeys, I. COMT Val158Met-stress interaction in psychosis: role of background psychosis risk. CNS Neurosci Ther 17, 612-619, doi:10.1111/j.1755-5949.2010.00213.x (2011).

50 Dumontheil, I., Roggeman, C., Ziermans, T., Peyrard-Janvid, M., Matsson, H., Kere, J. \& Klingberg, T. Influence of the COMT genotype on working memory and brain activity changes during development. Biol Psychiatry 70, 222-229, doi:10.1016/j.biopsych.2011.02.027 (2011).

51 Lajin, B., Alachkar, A., Hamzeh, A. R., Michati, R. \& Alhaj, H. No association between Val158Met of the COMT gene and susceptibility to schizophrenia in the Syrian population. N Am J Med Sci 3, 176-178, doi:10.4297/najms.2011.3176 (2011).

52 Raznahan, A., Greenstein, D., Lee, Y., Long, R., Clasen, L., Gochman, P., Addington, A., Giedd, J. N., Rapoport, J. L. \& Gogtay, N. Catechol-o-methyl transferase (COMT) val158met polymorphism and adolescent cortical development in patients with childhood-onset schizophrenia, their non-psychotic siblings, and healthy controls. Neuroimage 57, 1517-1523, doi:10.1016/j.neuroimage.2011.05.032 (2011).

53 Lopez-Garcia, P., Young Espinoza, L., Molero Santos, P., Marin, J. \& Ortuno Sanchez-Pedreno, F. Impact of COMT genotype on cognition in schizophrenia spectrum patients and their relatives. Psychiatry Res, doi:10.1016/j.psychres.2012.09.043 
(2012).

54 Singh, J. P., Volavka, J., Czobor, P. \& Van Dorn, R. A. A meta-analysis of the Val158Met COMT polymorphism and violent behavior in schizophrenia. PLoS One 7, e43423, doi:10.1371/journal.pone.0043423 (2012).

55 Ira, E., Zanoni, M., Ruggeri, M., Dazzan, P. \& Tosato, S. COMT, neuropsychological function and brain structure in schizophrenia: a systematic review and neurobiological interpretation. J Psychiatry Neurosci 38, 120178, doi:10.1503/jpn.120178 (2013).

56 Roffman, J. L., Gollub, R. L., Calhoun, V. D., Wassink, T. H., Weiss, A. P., Ho, B. C., White, T., Clark, V. P., Fries, J., Andreasen, N. C., Goff, D. C. \& Manoach, D. S. MTHFR 677C --> T genotype disrupts prefrontal function in schizophrenia through an interaction with COMT 158Val --> Met. Proc Natl Acad Sci U S A 105, 17573-17578, doi:10.1073/pnas.0803727105 (2008).

57 Alonso, P., Lopez-Sola, C., Gratacos, M., Fullana, M. A., Segalas, C., Real, E., Cardoner, N., Soriano-Mas, C., Harrison, B. J., Estivill, X. \& Menchon, J. M. The interaction between Comt and Bdnf variants influences obsessive-compulsive-related dysfunctional beliefs. J Anxiety Disord 27, 321-327, doi:10.1016/j.janxdis.2013.02.012 (2013).

58 Mancama, D., Mata, I., Kerwin, R. W. \& Arranz, M. J. Choline acetyltransferase variants and their influence in schizophrenia and olanzapine response. Am J Med Genet B Neuropsychiatr Genet 144B, 849-853, doi:10.1002/ajmg.b.30468 (2007).

59 Lundblad, M. S., Stark, K., Eliasson, E., Oliw, E. \& Rane, A. Biosynthesis of epoxyeicosatrienoic acids varies between polymorphic CYP2C enzymes. Biochem Biophys Res Commun 327, 1052-1057, doi:10.1016/j.bbrc.2004.12.116 (2005).

60 Sim, S. C. \& Ingelman-Sundberg, M. Update on allele nomenclature for human cytochromes P450 and the Human Cytochrome P450 Allele (CYP-allele) Nomenclature Database. Methods Mol Biol 987, 251-259, doi:10.1007/978-1-62703321-3_21 (2013).

61 Nelson, D. R., Zeldin, D. C., Hoffman, S. M., Maltais, L. J., Wain, H. M. \& Nebert, D. W. Comparison of cytochrome P450 (CYP) genes from the mouse and human genomes, including nomenclature recommendations for genes, pseudogenes and alternative-splice variants. Pharmacogenetics and Genomics 14, 1-18 (2004).

62 Pigott, T. A. \& Seay, S. M. A review of the efficacy of selective serotonin reuptake inhibitors in obsessive-compulsive disorder. J Clin Psychiatry 60, 101-106 (1999).

63 Pigott, T. A., Pato, M. T., Bernstein, S. E., Grover, G. N., Hill, J. L., Tolliver, T. J. \& Murphy, D. L. Controlled comparisons of clomipramine and fluoxetine in the treatment of obsessive-compulsive disorder. Behavioral and biological results. Arch Gen Psychiatry 47, 926-932 (1990).

64 Ring, B. J., Eckstein, J. A., Gillespie, J. S., Binkley, S. N., VandenBranden, M. \& Wrighton, S. A. Identification of the human cytochromes p450 responsible for in vitro formation of R- and S-norfluoxetine. J Pharmacol Exp Ther 297, 1044-1050 (2001).

65 Zhou, S. F., Liu, J. P. \& Chowbay, B. Polymorphism of human cytochrome P450 enzymes and its clinical impact. Drug Metab Rev 41, 89-295, doi:10.1080/03602530902843483 (2009).

66 Johnson, M. R., Wang, K., Tillmanns, S., Albin, N. \& Diasio, R. B. Structural Organization of the Human Dihydropyrimidine Dehydrogenase Gene. Cancer Research 57, 1660-1663 (1997).

67 Shestopal, S. A., Johnson, M. R. \& Diasio, R. B. Molecular cloning and characterization of the human dihydropyrimidine dehydrogenase promoter. Biochimica et Biophysica Acta (BBA) - Gene Structure and Expression 1494, 162-169, doi:http://dx.doi.org/10.1016/S0167-4781(00)00213-X (2000).

68 Sacco, J. C., Abouraya, M., Motsinger-Reif, A., Yale, S. H., McCarty, C. A. \& Trepanier, L. A. Evaluation of polymorphisms in the sulfonamide detoxification genes NAT2, CYB5A, and CYB5R3 in patients with sulfonamide hypersensitivity. Pharmacogenetics and Genomics 22, 733-740, doi:10.1097/FPC.0b013e328357a735 (2012).

69 Bozok Cetintas, V., Erer, O. F., Kosova, B., Ozdemir, I., Topcuoglu, N., Aktogu, S. \& Eroglu, Z. Determining the relation between $\mathrm{N}$-acetyltransferase-2 acetylator phenotype and antituberculosis drug induced hepatitis by molecular biologic tests. Tuberk Toraks 56, 81-86 (2008).

70 ACMG. (2013).

71 Conn, J. VA to update VistA EHR. Mod Healthc 41, 17 (2011).

72 Protti, D. \& Groen, P. Implementation of the Veterans Health Administration VistA clinical information system around the world. Healthc $Q$ 11, 83-89 (2008).

73 Kuzmak, P. M. \& Dayhoff, R. E. The Department of Veterans Affairs integration of imaging into the healthcare enterprise using the VistA Hospital Information System and Digital Imaging and Communications in Medicine. J Digit Imaging 11, 5364 (1998).

74 Brown, S. H., Lincoln, M. J., Groen, P. J. \& Kolodner, R. M. VistA--U.S. Department of Veterans Affairs national-scale HIS. Int J Med Inform 69, 135-156 (2003).

75 Fins, J. J., Dorfman, G. S. \& Pancrazio, J. J. Challenges to deep brain stimulation: a pragmatic response to ethical, fiscal, and regulatory concerns. Ann N Y Acad Sci 1265, 80-90, doi:10.1111/j.1749-6632.2012.06598.x (2012).

76 Synofzik, M., Fins, J. J. \& Schlaepfer, T. E. A neuromodulation experience registry for deep brain stimulation studies in psychiatric research: rationale and recommendations for implementation. Brain Stimul 5, 653-655, doi:10.1016/j.brs.2011.10.003 (2012).

77 Fins, J. J., Schlaepfer, T. E., Nuttin, B., Kubu, C. S., Galert, T., Sturm, V., Merkel, R. \& Mayberg, H. S. Ethical guidance for the management of conflicts of interest for researchers, engineers and clinicians engaged in the development of therapeutic deep brain stimulation. J Neural Eng 8, 033001, doi:10.1088/1741-2560/8/3/033001 (2011).

78 Fins, J. J., Mayberg, H. S., Nuttin, B., Kubu, C. S., Galert, T., Sturm, V., Stoppenbrink, K., Merkel, R. \& Schlaepfer, T. E. Misuse of the FDA's humanitarian device exemption in deep brain stimulation for obsessive-compulsive disorder. Health Aff (Millwood) 30, 302-311, doi:10.1377/hlthaff.2010.0157 (2011).

79 Fins, J. J. \& Schiff, N. D. Conflicts of interest in deep brain stimulation research and the ethics of transparency. J Clin Ethics 
21, 125-132 (2010).

80 Fins, J. J. Deep Brain Stimulation, Free Markets and the Scientific Commons: Is It time to Revisit the Bayh-Dole Act of 1980? Neuromodulation 13, 153-159, doi:10.1111/j.1525-1403.2009.00238.x (2010).

81 Erickson-Davis, C. Ethical concerns regarding commercialization of deep brain stimulation for obsessive compulsive disorder. Bioethics 26, 440-446, doi:10.1111/j.1467-8519.2011.01886.x (2012).

82 Kim, T. I., McCall, J. G., Jung, Y. H., Huang, X., Siuda, E. R., Li, Y., Song, J., Song, Y. M., Pao, H. A., Kim, R. H., Lu, C., Lee, S. D., Song, I. S., Shin, G., Al-Hasani, R., Kim, S., Tan, M. P., Huang, Y., Omenetto, F. G., Rogers, J. A. \& Bruchas, M. R. Injectable, cellular-scale optoelectronics with applications for wireless optogenetics. Science 340, 211-216, doi:10.1126/science.1232437 (2013).

83 Alivisatos, A. P., Andrews, A. M., Boyden, E. S., Chun, M., Church, G. M., Deisseroth, K., Donoghue, J. P., Fraser, S. E., Lippincott-Schwartz, J., Looger, L. L., Masmanidis, S., McEuen, P. L., Nurmikko, A. V., Park, H., Peterka, D. S., Reid, C., Roukes, M. L., Scherer, A., Schnitzer, M., Sejnowski, T. J., Shepard, K. L., Tsao, D., Turrigiano, G., Weiss, P. S., Xu, C., Yuste, R. \& Zhuang, X. Nanotools for neuroscience and brain activity mapping. ACS Nano 7, 1850-1866, doi:10.1021/nn4012847 (2013).

84 Alivisatos, A. P., Chun, M., Church, G. M., Deisseroth, K., Donoghue, J. P., Greenspan, R. J., McEuen, P. L., Roukes, M. L., Sejnowski, T. J., Weiss, P. S. \& Yuste, R. Neuroscience. The brain activity map. Science 339, 1284-1285, doi:10.1126/science.1236939 (2013).

85 Pais-Vieira, M., Lebedev, M., Kunicki, C., Wang, J. \& Nicolelis, M. A. A brain-to-brain interface for real-time sharing of sensorimotor information. Sci Rep 3, 1319, doi:10.1038/srep01319 (2013).

86 Thomson, E. E., Carra, R. \& Nicolelis, M. A. Perceiving invisible light through a somatosensory cortical prosthesis. Nat Commun 4, 1482, doi:10.1038/ncomms2497 (2013).

87 Nicolelis, M. A. Mind in motion. Sci Am 307, 58-63 (2012).

88 Moreno-De-Luca, A., Myers, S. M., Challman, T. D., Moreno-De-Luca, D., Evans, D. W. \& Ledbetter, D. H. Developmental brain dysfunction: revival and expansion of old concepts based on new genetic evidence. The Lancet Neurology 12, 406-414 (2013).

89 Nielsen, R., Paul, J. S., Albrechtsen, A. \& Song, Y. S. Genotype and SNP calling from next-generation sequencing data. Nat Rev Genet 12, 443-451, doi:10.1038/nrg2986 (2011).

90 O'Rawe, J., Jiang, T., Sun, G., Wu, Y., Wang, W., Hu, J., Bodily, P., Tian, L., Hakonarson, H., Johnson, W. E., Wei, Z., Wang, K. \& Lyon, G. J. Low concordance of multiple variant-calling pipelines: practical implications for exome and genome sequencing. Genome Med 5, 28, doi:10.1186/gm432 (2013).

91 Klei, L., Sanders, S. J., Murtha, M. T., Hus, V., Lowe, J. K., Willsey, A. J., Moreno-De-Luca, D., Yu, T. W., Fombonne, E., Geschwind, D., Grice, D. E., Ledbetter, D. H., Lord, C., Mane, S. M., Lese Martin, C., Martin, D. M., Morrow, E. M., Walsh, C. A., Melhem, N. M., Chaste, P., Sutcliffe, J. S., State, M. W., Cook, E. H., Jr., Roeder, K. \& Devlin, B. Common genetic variants, acting additively, are a major source of risk for autism. Mol Autism 3, 9, doi:10.1186/2040-2392-3-9 (2012).

92 Mitchell, K. J. \& Porteous, D. J. Rethinking the genetic architecture of schizophrenia. Psychol Med 41, 19-32, doi:10.1017/S003329171000070X (2011).

93 Mitchell, K. J. What is complex about complex disorders? Genome Biol 13, 237, doi:10.1186/gb-2012-13-1-237 (2012).

94 Visscher, P. M., Goddard, M. E., Derks, E. M. \& Wray, N. R. Evidence-based psychiatric genetics, AKA the false dichotomy between common and rare variant hypotheses. Mol Psychiatry, doi:10.1038/mp.2011.65 (2011).

95 Biesecker, B. B. \& Peay, H. L. Genomic sequencing for psychiatric disorders: promise and challenge. Int $J$ Neuropsychopharmacol, 1-6, doi:10.1017/S146114571300014X (2013).

96 Lyon, G. J. There is nothing "Incidental" about Unrelated Findings. Personalized Medicine

9, 163-166, doi:DOI 10.2217/pme.11.98 (doi:10.2217/pme.11.98) (2012).

97 ACMG. (2013).

98 Yu, J. H., Jamal, S. M., Tabor, H. K. \& Bamshad, M. J. Self-guided management of exome and whole-genome sequencing results: changing the results return model. Genet Med, doi:10.1038/gim.2013.35 (2013).

99 Support the Proposed Federal Rule to Expand the Rights of Patients to Access Their Test Results, $<$ http://strataconf.com/rx2012/public/content/consensus $>$ (2013).

100Lyon, G. J. Personalized medicine: Bring clinical standards to human-genetics research. Nature 482, 300-301, doi:10.1038/482300a (2012).

101Lyon, G. J. Guest post: Time to bring human genome sequencing into the clinic, $<$ http://www.genomesunzipped.org/2012/02/guest-post-time-to-bring-human-genome-sequencing-into-the-clinic.php > (2012). 102 Sacks, O. W. An anthropologist on Mars : seven paradoxical tales. 1st edn, (Alfrd A. Knopf, 1995).

103 Sacks, O. W. The man who mistook his wife for a hat and other clinical tales. 1st Touchstone edn, (Simon \& Schuster, 1998). 104Luria, A. R. The man with a shattered world; the history of a brain wound. (Basic Books, 1972).

105Luria, A. R. The mind of a mnemonist : a little book about a vast memory. (H. Regnery, 1976).

106Van Horn, J. D., Irimia, A., Torgerson, C. M., Chambers, M. C., Kikinis, R. \& Toga, A. W. Mapping connectivity damage in the case of Phineas Gage. PLoS One 7, e37454, doi:10.1371/journal.pone.0037454 (2012).

107Ratiu, P., Talos, I. F., Haker, S., Lieberman, D. \& Everett, P. The tale of Phineas Gage, digitally remastered. J Neurotrauma 21, 637-643, doi:10.1089/089771504774129964 (2004).

108Eichenbaum, H. What H.M. taught us. J Cogn Neurosci 25, 14-21, doi:10.1162/jocn_a_00285 (2013).

109 Worthey, E. A., Mayer, A. N., Syverson, G. D., Helbling, D., Bonacci, B. B., Decker, B., Serpe, J. M., Dasu, T., Tschannen, M. R., Veith, R. L., Basehore, M. J., Broeckel, U., Tomita-Mitchell, A., Arca, M. J., Casper, J. T., Margolis, D. A., Bick, D. P., Hessner, M. J., Routes, J. M., Verbsky, J. W., Jacob, H. J. \& Dimmock, D. P. Making a definitive diagnosis: successful clinical application of whole exome sequencing in a child with intractable inflammatory bowel disease. Genetics in medicine : official 


\section{Figure 1}

Sagittal and transverse computed tomography (CT) images of the brain and skull of M.A.

We show here sagittal and transverse sections taken from CT scans. Imaging was performed before (A) and after (B) M.A. received deep brain stimulation surgery for his treatment refractory OCD. Two deep brain stimulator probes can be seen to be in place from a bifrontal approach (B), with tips of the probes located in the region of the hypothalamus. Leads traverse through the left scalp soft tissues. Streak artifact from the leads somewhat obscures visualization of the adjacent bifrontal and left parietal parenchyma. We did not observe any intracranial hemorrhage, mass effect or midline shift or extra-axial fluid collection. Brain parenchyma was normal in volume and contour. 

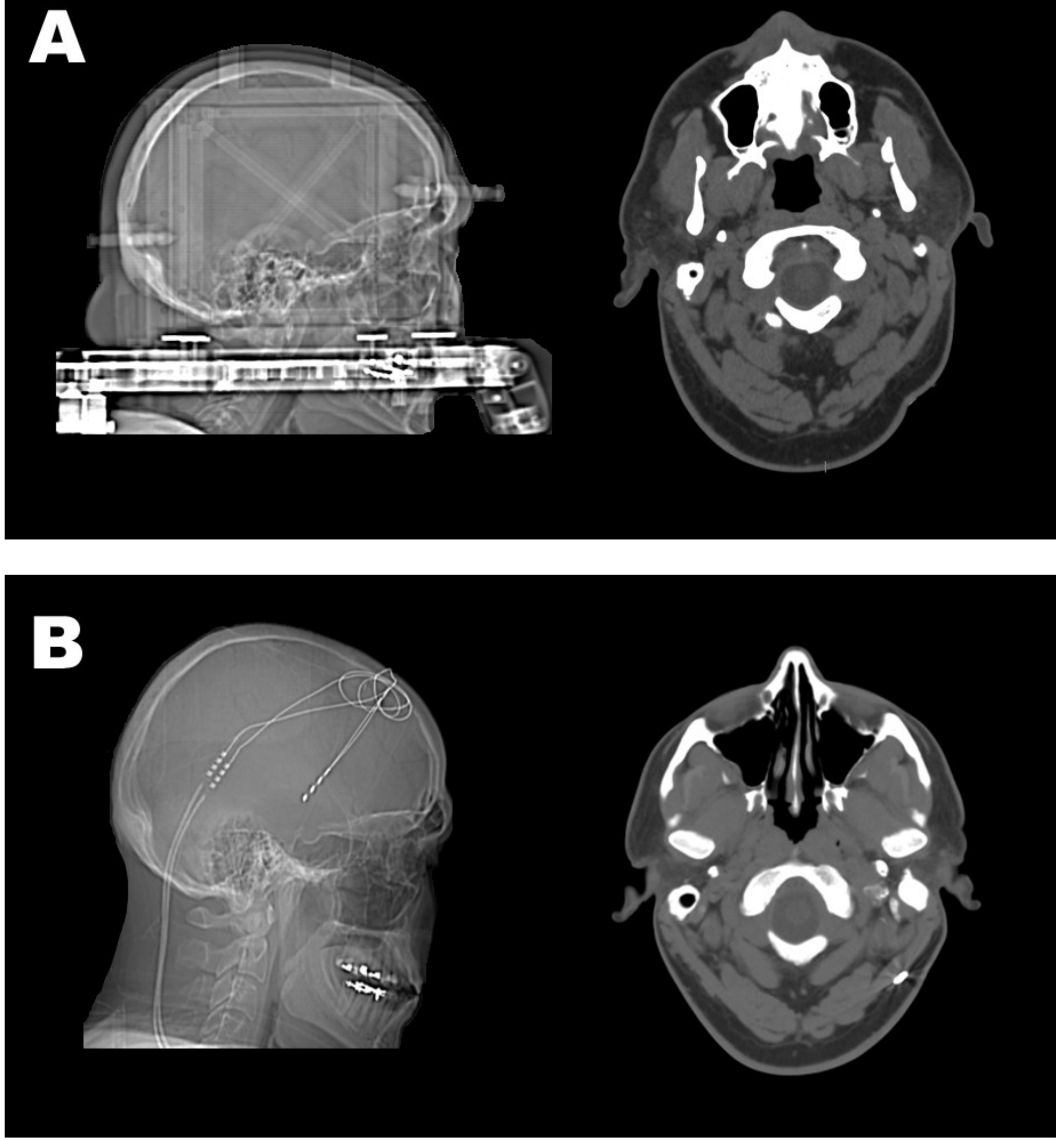


\section{Figure 2}

Implementation of the analytic-interpretive split model for the clinical incorporation of a whole genome.

We have implemented the analytic-interpretive split model here with M.A., with WGS being performed in a CLIA certified and CAP accredited lab at Illumina as part of the Individual Genome Sequencing test developed by them. The WGS acts as a discrete deliverable clinical unit from which multiple downstream interpretive analyses were performed. We used the ERDS CNV caller, the Golden Helix SVS CNAM for CNV calling, and the Omicial Opal and the AssureRx Health Inc. pipelines for variant annotation and clinical interpretation of genomic variants. By archiving and offering to him the encrypted hard drive containing his "raw" sequencing data, any number of people, including the individual and/or his/her health care providers can analyze his genome for years to come. Abbreviations are as follows: CLIA, Clinical Laboratory Improvement Amendments; CAP, College of American Pathologists; CASAVA, Consensus Assessment of Sequence and Variation; ERDS, Estimation by Read Depth with SNVs; CNAM, Copy Number Analysis Method; WGS, Whole Genome Sequencing. 
TruSight Individual Genome Sequencing (IGS) test using the Illumina HiSeq2000 in the Illumina Clinical Services Laboratory (CLIA-certified, CAP-accredited)

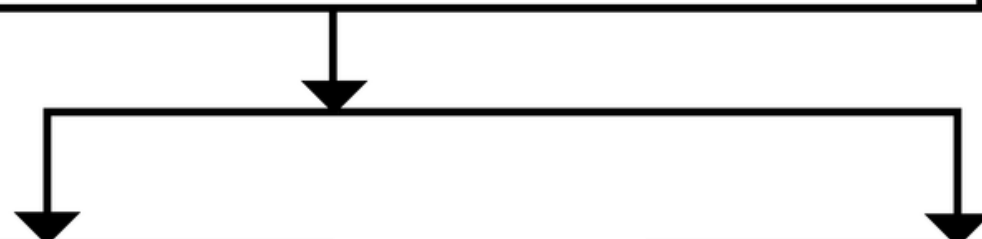

Reads were mapped, and variants called (SNVs, Indels) using

CASAVA

CNVs were called using ERDS and CNAM with WGS and genotyping array data

\section{Illumina WGS clinical}

evaluation, which included the

evaluation of 344 genes

(Indels and other structural variations are not validated variant types and were not evaluated in the clinical evaluation of these genes)
All variants (including Indels and other structural variants detected by the CASAVA pipeline) were annotated and prioritized by clinical relevance using the Omicia Opal system as well as with AssureRx Health Inc.

After consultation with a genetic counselor, the genetic findings were returned to M.A. with the option given to him to keep the raw data (which he declined). SNVs and Indels that were detected by the CASAVA pipeline were also converted to the GVFclin file format so that his WGS data could be, in the future, incorporated into his electronic medical record. 


\section{Figure 3}

Yale Brown Obsessive Compulsive Scale (YBOCS) scores were measured for M.A over a three year and seven months period of time.

A time series plot $(\mathbf{A})$ shows a steady decline in YBOCS scores over the period of time spanning his DBS surgery (s) and treatment. Incremental adjustments to neurostimulator voltage are plotted over a period of time following DBS surgery. Mean YBOCS scores are plotted for sets of measurements taken before and after Deep Brain Stimulation (DBS) surgery (B). A one-tailed unpaired t test with Welch's correction results in a $p$ value of 0.0099, demonstrating a significant difference between YBOCS scores measured before and after the time of surgery.
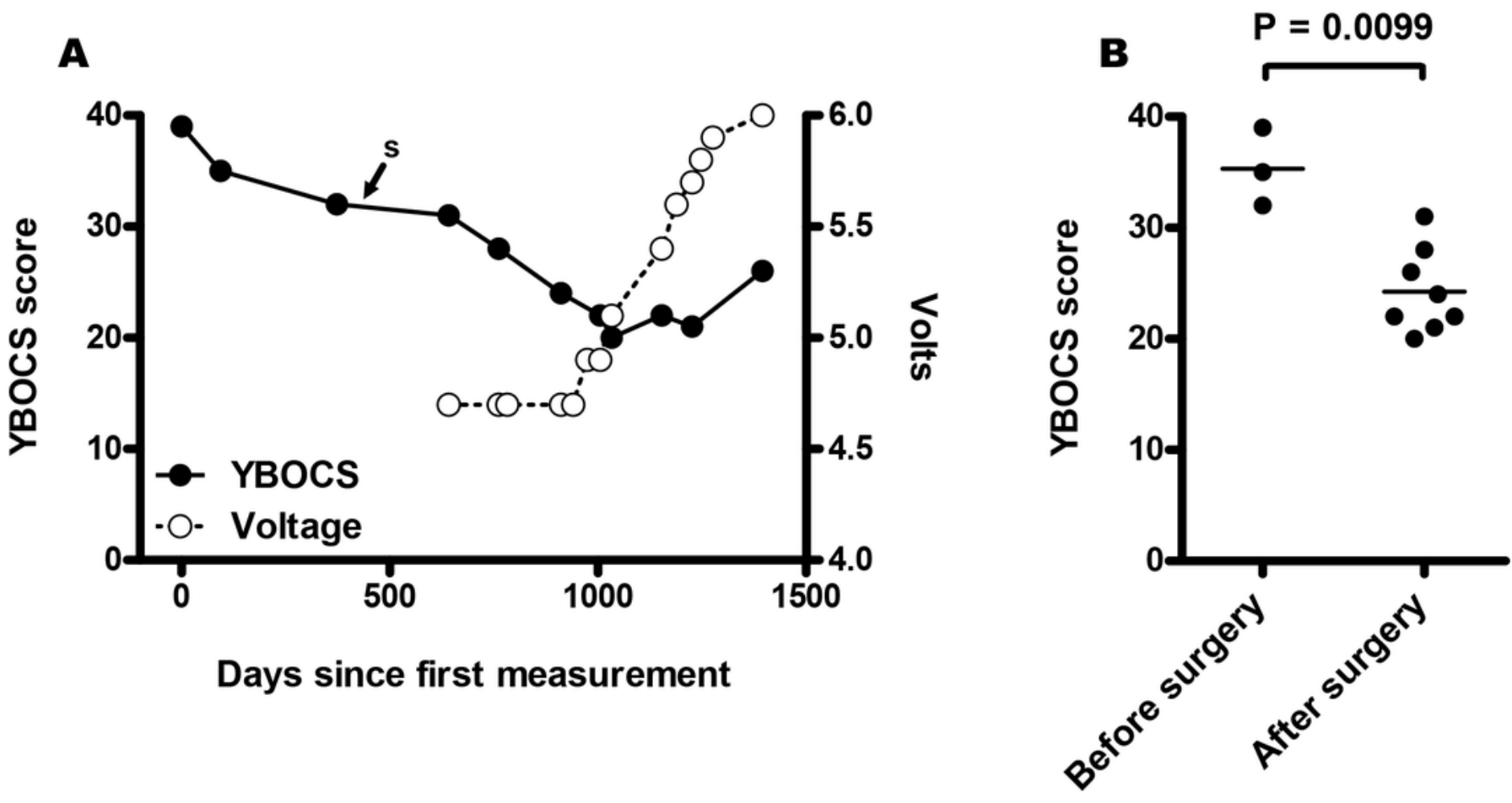


\section{Table 1 (on next page)}

A summary of three clinically relevant alleles found in the sequencing results of M.A.

Variations in MTHFR, BDNF, and ChAT were found to be of potential clinical relevance for this person, as they are all implicated in contributing to the susceptibility and development of many neuropsychiatric disorders that resemble those present within M.A. A brief summary of the characteristics of each variation is shown, including the gene name, genomic coordinates, amino acid change, zygosity, variation type, estimated population frequency and putative clinical significance. 


\begin{tabular}{|c|c|c|c|c|c|c|}
\hline Gene name & $\begin{array}{l}\text { Genomic } \\
\text { coordinates }\end{array}$ & $\begin{array}{l}\text { Amino acid } \\
\text { change }\end{array}$ & Zygosity & $\begin{array}{l}\text { Variation } \\
\text { type }\end{array}$ & $\begin{array}{l}\text { Population } \\
\text { Frequency }\end{array}$ & Clinical significance \\
\hline MTHFR & $\begin{array}{l}\text { chr1: } \\
11854476\end{array}$ & Glu $>$ Ala & heterozygous & non-synon & T:77\% G:23\% & $\begin{array}{l}\text { Susceptibility to psychoses, } \\
\text { schizophrenia occlusive } \\
\text { vascular disease, neural tube } \\
\text { defects, colon cancer, acute } \\
\text { leukemia, and } \\
\text { methylenetetra-hydrofolate } \\
\text { reductase def-iciency }\end{array}$ \\
\hline BDNF & $\begin{array}{l}\text { chr11: } \\
27679916\end{array}$ & Val $>$ Met & heterozygous & non-synon & C:77\% T:23\% & $\begin{array}{l}\text { Susceptibility to OCD, } \\
\text { psychosis, and diminished } \\
\text { response to exposure therapy }\end{array}$ \\
\hline CHAT & $\begin{array}{l}\text { chr10: } \\
50824117\end{array}$ & Asp $>$ Asn & heterozygous & non-synon & G: $85 \%$ A: $15 \%$ & $\begin{array}{l}\text { Susceptibility to } \\
\text { schizophrenia and other } \\
\text { psychopathological disorders. }\end{array}$ \\
\hline
\end{tabular}

